\title{
Day-ahead Optimal Scheduling of Regenerative Electric Heating System Considering Load Imbalance
}

\author{
Fei Xu ${ }^{1}$, Ling $\mathrm{Hao}^{1, *}$, Lei Chen ${ }^{1}$, Qun Chen ${ }^{2}$, Yong Min ${ }^{1}$ \\ ${ }^{1}$ State Key Lab of Power Systems, Department of Electrical Engineering, Tsinghua University, Haidian District, Beijing 100084; \\ ${ }^{2}$ Key Laboratory for Thermal Science and Power Engineering of Ministry of Education, Department of Engineering Mechanics, Tsinghua \\ University, Haidian District, Beijing 100084
}

\begin{abstract}
For the regenerative electric heating system, on the premise of ensuring reliable heat supply to users, a day-ahead optimization scheduling method for the regenerative electric heating system considering the load imbalance is proposed. First, users' heating demand under normal working conditions and grid power rationing scenarios are calculated by estimate index method. Then, in order to match the heating demand of users and reduce the load imbalance caused by thermal storage electric heating in the distribution network, comprehensive consideration of grid constraints and the adjustable capacity of regenerative electric heating load, the operating strategy of the thermal storage electric heating system is studied. Reasonable control of heat storage and release in regenerative electric heating can not only reduce the distribution line pressure during heating period, but also maximize the accommodation of low-cost electricity such as surplus renewable energy and improve the economic benefits of the system. Taking the regenerative electric heating system in Chongli area of Zhangjiakou, Hebei Province as an example, the multi-objective optimal scheduling model is simulated and analyzed, and the feasibility and effectiveness of the proposed optimal scheduling strategy are verified.
\end{abstract}

\section{Introduction}

Coal-fired heating methods have led to serious environmental pollution problems in the northern region in winter. In order to achieve the clean heating rate of $70 \%$ in northern China in $2021^{[1]}$, it is imperative for the Beijing-Tianjin-Hebei region to complete the conversion of coal to electricity ${ }^{[2]}$. Electric heating has the advantages of pollution-free, convenient construction, flexible and controllable operation, and has become the first choice for clean heating in northern regions. However, the operating cost of electric heating equipment is high, and there is a problem of heating reliability when the power is cut off ${ }^{[3-4]}$. And direct heating electric heating equipment access to the distribution network is prone to high power consumption at the same time, large power consumption, and daily peak time overlap, the superposition effect will cause the phenomenon of 'peak increase', affecting the safety and stability of power system. In addition, when electric heating uses clean energy such as wind power and photovoltaic power for heating, as the installed scale increases, and the operating mode of 'heat-fixed electricity' exists for heating units ${ }^{[5]}$, this further exacerbates the phenomenon of wind curtailment and solar curtailment during the heating period in winter.

In response to the above-mentioned problems, thermal storage electric heating can meet the requirements of "non-stop heating" through the flexible controllability of the heat storage device. Thermal storage electric heating can realize the "peak-shaving and valley-filling" of the overall power load of the distribution network, and increase wind power, photovoltaic absorption capacity. Regenerative electric heating equipment can charge and heat storage device according to the user 's electricity consumption behavior during the period of low power consumption at night, and heat release during the peak period of electricity consumption can meet the heating demand. It can convert excess wind and solar energy into thermal energy to meet the heating demand during the peak period of electricity consumption, reduce the overlap with the daily peak of electricity consumption of users, and make the grid operation more smooth. In addition, heat storage in valley period can effectively reduce the heating cost of the system. In this field, some domestic and foreign scholars have conducted a lot of research: Literature [6-9] improved the flexibility and adjustability of the combined electric-thermal system and greatly improved the consumption of renewable energy by optimizing the capacity of the heat storage device. Literature [10-12] by evaluating the peak regulation capacity of the unit with heat storage device on the system, the optimal scheduling model with the minimum coal consumption at unit operation as the objective function was established. Literature [13] considered the uncertainty of wind power output, and through the electric and thermal output of the

\footnotetext{
* Corresponding author: Ling Hao, haolg@foxmail.com
} 
control system, the bilinear system optimization scheduling model was established with the objective function of minimum abandoned wind volume and minimum system operation cost. Literature [14] established the joint dispatch model for wind power, thermal power, cogeneration units and heat storage, compared with the wind power heating mode, and analyzed the coal-saving effects of two different schemes. Literature [15-16] based on the scenario method to describe the randomness of wind power output, established the optimal scheduling model for combined electric and heat systems with wind power and heat storage, and discussed the heat storage and release strategies of heat storage devices in different wind power scenarios. Literature [17] optimized the heat storage and heat release period of the heat storage device, and the optimal scheduling model for regenerative electric heating was established, which improved users' economy. The above-mentioned studies have focused on revealing the use of heat storage devices to promote the consumption of renewable energy ${ }^{[18-20]}$, or by optimizing the heat storage and heat release period of regenerate electric heating, only to improve the economy of system operation.

Based on the actual regenerative electric heating system in Hebei Province, in this paper, the day-ahead optimal dispatch model for the regenerative electric heating system that considers load imbalance is established. The model defines load imbalance index for the grid to meet the heating needs of users. Under the premise, consider its own optimized operation. That is, through reasonable control of the heat storage and release of the heat storage device, the operation state of the electric boiler is optimized and controlled, and the load imbalance disturbance caused by its operation to the power grid is reduced. The optimal dispatching model takes the minimum overall operating cost of the system as the objective constraint, and uses penalty fees to stabilize the influence of electric boilers on the distribution network under different dispatching operating states, as well as the power-cut load and heatcut load behavior of the grid. The feasibility of the proposed optimal scheduling model is verified by simulation analysis under normal working conditions scenario and electricity limiting of power grid scenario. The load imbalance index and the system heating cost before and after optimization are compared. According to the simulation results, the heat storage and release behavior of the thermal storage device under different scheduling operation conditions of the electric boiler is analyzed, and the feasibility and effectiveness of the proposed scheduling strategy are verified.

\section{Heat load demand analysis}

In the 'Three Norths' area of China, a large number of electric boilers are connected to the power grid during the heating period in winter. It is prone to have a high rate of electricity consumption at the same time, and the phenomenon of "peaking and adding to the peak" overlapping with the daily peak time of electricity consumption. Therefore, it is necessary to study the heating demand of users. Under the premise of meeting the heating demand, the heat storage and release of the heat storage device are optimized. The system stores heat during the low electricity price period to improve the economy. The power grid meets the heating demand of the user and also takes into account its own smooth and safe operation. This paper takes the regenerative electric heating system in Chongli District, Zhangjiakou, Hebei Province as an example, the heat load in the region is estimated and the heat load curve of user demand is calculated..

(1) Heating standard

The 'Measures for Heat Supply in Hebei Province' stipulates that during the heating period, the heating unit should ensure that the indoor temperature of the residents' living rooms and bathrooms is not lower than $18^{\circ} \mathrm{C}$. If the transmission capacity of the power grid is reduced due to special reasons and the electricity limiting of power grid, the minimum heating load demand of users should be ensured at this time. That is to ensure the personal safety of residents, avoid the serious consequences of heating recovery difficulties caused by freezing and cracking of the heating pipe network, and the lowest indoor temperature that users can withstand is $10^{\circ} \mathrm{C}$.

(2) Calculation method of heat load demand

The heat load demand is calculated using the estimation index method, and the formula is as follows.

$$
Q=q_{v} \cdot V_{m} \cdot\left(t_{n}-t_{w}\right) \times 10^{-3}
$$

where $Q$ is the heating load of the building, $\mathrm{kW} ; q_{v}$ is the heating volumetric heat index of the building, $\mathrm{W} /\left(\mathrm{m}^{3} \cdot{ }^{\circ} \mathrm{C}\right) ; V_{m}$ is the outer volume of the building, $\mathrm{m}^{3}$; $t_{n}$ is the calculated temperature in the heating room; $t_{w}$ is the calculated temperature outside the heating room ${ }^{[21]}$. The heating volumetric heat indicators of different user types are shown in Table 1.

Table 1. Building heating volume heat index

\begin{tabular}{|c|c|}
\hline Types & $\boldsymbol{q}_{\boldsymbol{v}}\left(\mathbf{W} /\left(\mathbf{m}^{3} \cdot{ }^{\circ} \mathbf{C}\right)\right)$ \\
\hline Office building & 0.37 \\
\hline Hospital & 0.35 \\
\hline School & 0.35 \\
\hline Residents & 0.3 \\
\hline
\end{tabular}

(3) Heat load demand curve

The total heating area in this area is $50000 \mathrm{~m}^{2}$, of which the school area is $5000 \mathrm{~m}^{2}$, the office building area is $10000 \mathrm{~m}^{2}$, the residential user area is $30000 \mathrm{~m}^{2}$, and the hospital area is $5000 \mathrm{~m}^{2}$.

Calculated from the above data, the thermal load demand curve in a certain area of Zhangjiakou Chongli District under normal operating conditions and electricity limiting of power grid are shown in Fig. 1. 


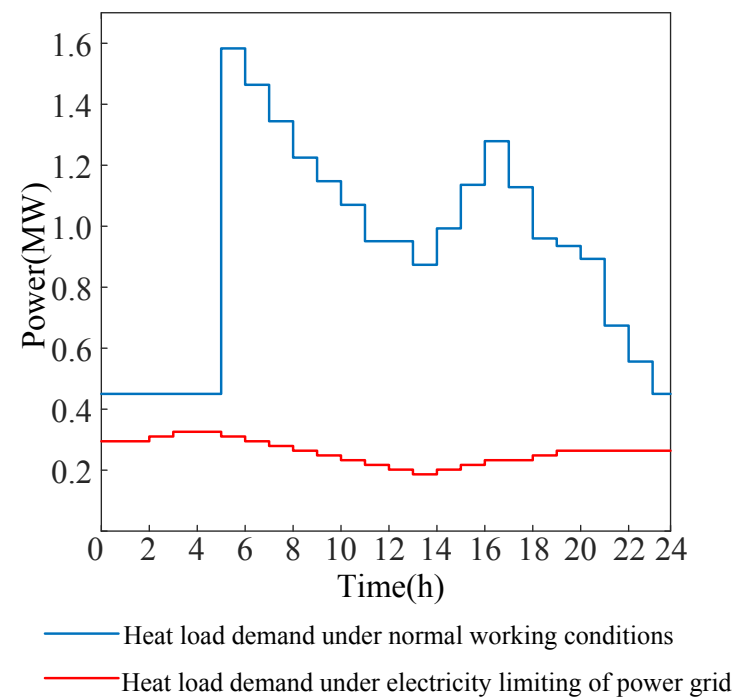

Figure 1. Heat load demand curve

\section{Day-ahead optimization scheduling model}

The regenerative electric boiler is used for heating in Chongli District, Zhangjiakou, Hebei Province. The thermal storage device stores or releases heat by controlling the temperature of the hot water. During the low load period, part of the heat generated by the electric boiler is directly supplied to the user, and the rest of the heat is stored in the heat storage tank. When the heat load increases, the heat storage device releases heat to the user. Using the flexible control-ability of the heat storage device, it can operate in conjunction with the electric boiler to control the power operation status of the electric boiler according to the heating demand of the user, the dispatching demand of the power grid and the electricity price factor. Utilizing the adjustable capacity of thermal storage electric heating load to ensure the stability of heating and form a continuous and stable electricity load, which improves the carrying capacity of the distribution line and the economy of system operation. The system diagram is shown in Fig. 2.

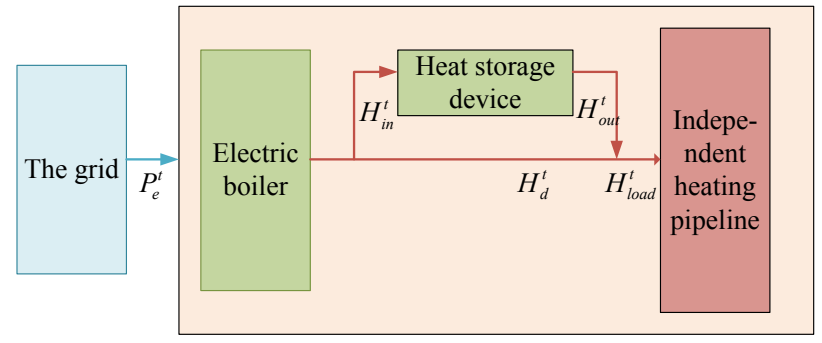

Figure 2. Schematic diagram of regenerative electric heating system

From Fig. 2, $P_{e}^{t}$ is the electric power consumed by the thermal storage electric boiler at time $t ; H_{i n}^{t}$ is the input power of the thermal storage device at time $t ; S_{e h}^{t}$ is the total stored heat of the thermal storage device at time $t ; H_{\text {out }}^{t}$ is the output power of the thermal storage device at time $t ; H_{d}^{t}$ is the direct heat supply of the electric boiler to the heat load at time $t ; H_{\text {load }}^{t}$ is the heat load at time $t$.

\subsection{Objective function}

The objective function is represented by the minimum operating cost of the whole system, including the operating cost of the regenerative electric boiler, the penalty cost caused by the load imbalance, the power cut load and the heat load penalty cost. The peak-valley difference is commonly used as the load imbalance index in distribution network. In order to more comprehensively reflect the 24-hour load imbalance, this paper integrate the absolute value of the difference between the load at each time and the average load line of the day, and defines it as the load imbalance. The load imbalance is used to more comprehensively describe the impact of the optimal operation of the regenerative electric boiler on the load balance of the distribution network. The formula is expressed as

$$
\min C=\sum_{t=1}^{t=T} c(t) \cdot P_{e}^{t}+\alpha \int_{1}^{T}\left|P_{c}^{t}-P_{m e n}\right| d t+\sum_{t=1}^{t=T} \beta \cdot P_{\text {loss }}^{t}+\sum_{t=1}^{t=T} \lambda \cdot H_{\text {loss }}^{t}
$$

where $C$ is the operating cost of the system; $P_{e}^{t}$ is the electric power consumed by the electric boiler with thermal storage at time $t ; c(t)$ is the real-time electricity price; $T$ takes 96 , representing 96 periods with $15 \mathrm{~min}$ as the step length in 24 hours a day. $P_{c}^{t}$ is the overall electrical load of the system at time $t$, including the user's electric power and the electric power consumed by the electric boiler; $P_{m e n}$ is the average load power; $\int_{1}^{T}\left|P_{c}^{t}-P_{m e n}\right| d t$ is the load imbalance; $P_{\text {loss }}^{t}$ is the power cut load at time $t ; H_{\text {loss }}^{t}$ is the heat cut load at time $t ; \alpha, \beta, \lambda$ are the penalty factors, where $\alpha$ is taken as 0.12 during the low load period and 0.02 during other periods; $\beta$ takes 2 and $\lambda$ takes 3 .

\subsection{Constraint condition}

(1) Distribution network power flow equation constraints

$$
\left\{\begin{array}{l}
P_{i}=U_{i} \sum_{j \in 1}^{j=n} U_{j}\left(G_{i j} \cos \theta_{i j}+B_{i j} \sin \theta_{i j}\right) \\
Q_{i}=U_{i} \sum_{j \in 1}^{j=n} U_{j}\left(G_{i j} \sin \theta_{i j}-B_{i j} \cos \theta_{i j}\right)
\end{array}\right.
$$

where $P_{i}$ is the injected active power of node $i ; Q_{i}$ is the injected reactive power of node $i ; U_{i}$ is the voltage amplitude of node $i ; G_{i j}$ and $B_{i j}$ are the conductance and susceptance of branch $i j$, respectively; $\theta_{i j}$ is the voltage phase difference between node $i$ and node $j ; n$ is the number of nodes. Set the root node of the distribution network as the reference node.

(2) Network security constraints

$$
P_{l, \text { min }}^{B} \leq P_{l, t}^{B} \leq P_{l, \text { max }}^{B}
$$


where $P_{l, t}^{B}$ is the electric power of line $l$ during the $t$ period; $P_{l, \text { min }}^{B}$ and $P_{l, \text { max }}^{B}$ are the lower and upper limit power of line $l$, respectively. This constraint indicates that the power flow of each line cannot exceed the limit during the dispatch period.

(3) Operational constraints of electric heating devices 1)Electric heat conversion constraints

$$
C_{\mathrm{eh}} P_{e}^{t}=H_{\text {in }}^{t}+H_{d}^{t}
$$

where $P_{e}^{t}$ is the electric power consumed by the electric boiler at time $t ; C_{\mathrm{eh}}$ is the electric heat conversion coefficient of the electric boiler; $H_{i n}^{t}$ is the heat storage capacity of the heat storage device at time $t ; H_{d}^{t}$ is the power of the electric boiler to directly heat the heat load at time $t$, This formula is a constraint on the relationship between the electrical energy consumed by the electric boiler and the thermal energy produced.

2) Electric power constraints

$$
0 \leq P_{\mathrm{e}}^{t} \leq P_{\mathrm{e}, \max }
$$

where $P_{\mathrm{e}, \max }$ is the upper limit of the electric power used by the electric boiler, which reflects the limitation of the electric heating rate.

(4) Heat storage device constraints

1) Heat storage balance equation

$$
S_{\text {eh }}^{t}=S_{\text {eh }}^{t-1}+H_{\text {in }}^{t}-H_{\text {out }}^{t}-k_{\text {loss }} S_{\text {eh }}^{t-1}
$$

where $k_{\text {loss }}$ is the heat leakage loss coefficient of the heat storage device, and the heat storage of the heat storage device is affected by the heat storage and release power and the heat leakage loss, and $k_{\text {loss }} S_{\text {eh }}^{t-1}$ represents the heat leakage loss of the heat storage device at $t-1$.

2) Cycle constraint of heat storage device

$$
S_{e h}^{0}=S_{e h}^{24}
$$

This constraint reflects that the heat storage device need return to the original heat storage value after a period of operation (for example, 1 day).

3) Heat load balance equation

$$
H_{d}^{t}+H_{\text {out }}^{t}=H_{\text {load }}^{t}
$$

where $H_{\text {load }}^{t}$ is the thermal load power of the system at time $t$; this constraint indicates that the power released by the heat storage device plus the heating power directly supplied by the electric boiler must meet the thermal load demand.

4) Restriction on heat storage and release rate of heat storage device

$$
\left\{\begin{array}{l}
0 \leq H_{\text {in }}^{t} \leq H_{\text {in,max }}^{t} \\
0 \leq H_{\text {out }}^{t} \leq H_{\text {out } \text {, max }}^{t}
\end{array}\right.
$$

where $H_{i n \text {, max }}^{t}$ is the maximum heat storage rate; $H_{\text {out, max }}^{t}$ is the maximum heat release rate. This constraint reflects that the heat storage and release rate is limited by the heat transfer rate of the heat exchanger.

5) Capacity constraints

$$
0 \leq S_{e h}^{t} \leq S_{e h, \max }
$$

where $S_{e h, \text { max }}$ is the maximum heat storage capacity of the heat storage tank.

\section{Case analysis}

\subsection{The case parameter}

In this paper, taking the distribution network system of thermal storage electric heating in Zhangjiakou area of Hebei Province as the example. Considering the normal working conditions and power grid power limitation, the optimal operation of regenerative electric boiler is analyzed by using the above mathematical model and the 96 point heating demand curve. The electricity heating cost of users before and after optimization and the electric load imbalance of power grid after connecting to the distribution network are compared. The peak electricity price period is from 08:00 to 20:00, and the electricity price standard is 0.5 yuan $/(\mathrm{kW} \cdot \mathrm{h})$; the valley electricity price period is from 20:00 to 08:00 the next day, and the electricity price standard is 0.22 yuan $/(\mathrm{kW} \cdot \mathrm{h})$.

\subsection{Optimal scheduling result analysis}

\subsubsection{Normal working condition of power grid}

When the power grid is working normally, during the heating period, the heating unit shall ensure that the indoor temperature of the residential living room and toilet is not less than $18{ }^{\circ} \mathrm{C}$. On the premise of meeting the heating demand, by optimizing the operation state of the electric boiler and the storage and release period of the heat storage device, the load imbalance on the power supply feeder of the regenerative electric boiler is the lowest, and the electric heating cost of the system is the lowest. The operating curve is shown in Fig. 3.

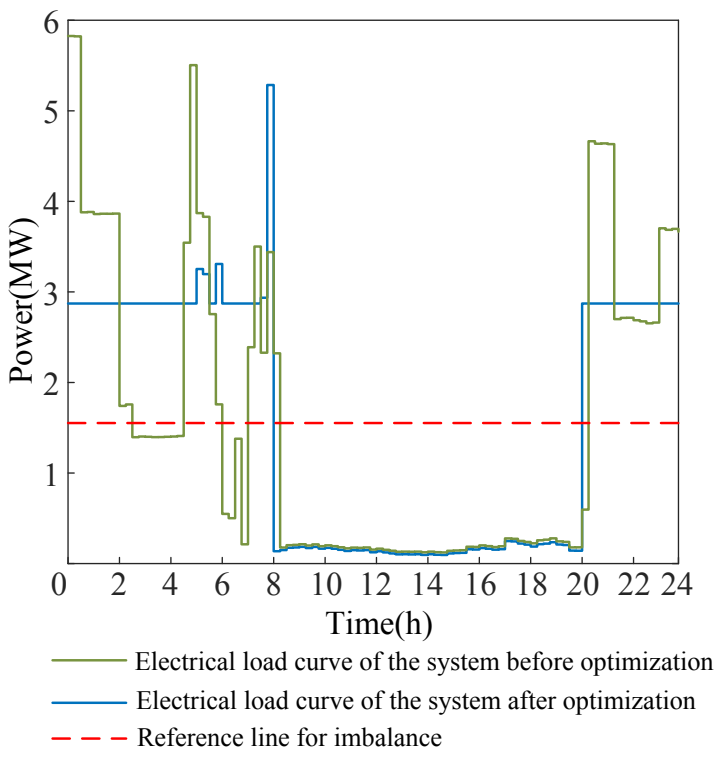

Figure 3. Grid electric load curve

From Fig. 3, it can be seen that the power load curve of the power grid without optimized operation of the thermal storage electric boiler fluctuates greatly, which 
will bring greater pressure to the distribution network. The optimized grid electric load curve can basically remain stable from 20:00 to 8:00, and the curve only has a peak at 8:00. It shows that the electric boiler runs smoothly after optimized dispatching, so that the power load of the power grid can also be maintained in a gentle state. By comparing with the load imbalance reference line, it can be seen that the distance difference between the optimized grid electrical load curve and the reference line is smaller, indicating that the optimized grid load imbalance is reduced. Optimized control of electric boilers to operate during low electricity prices improves the system's economy. The calculation data in Table 2 can be reflected directly.

Table 2. Load imbalance and electric heating costs before and after optimization

\begin{tabular}{|l|c|c|}
\hline \multicolumn{1}{|c|}{ Project } & $\begin{array}{c}\text { Before } \\
\text { optimization }\end{array}$ & Optimized \\
\hline Load imbalance $(\mathrm{kWh})$ & 14346.31 & 904.8198 \\
\hline Electric heating costs $(¥)$ & 5063.029 & 4809.687 \\
\hline
\end{tabular}

It can be seen from the above data that the user heating cost is reduced by using the optimal scheduling model in this paper. The optimized grid load imbalance is only $1 / 14$ of that before optimization, which greatly reduces the distribution network lines pressure during the heating period.

The operation curve of the regenerative electric boiler before and after optimization is showed in Fig. 4.

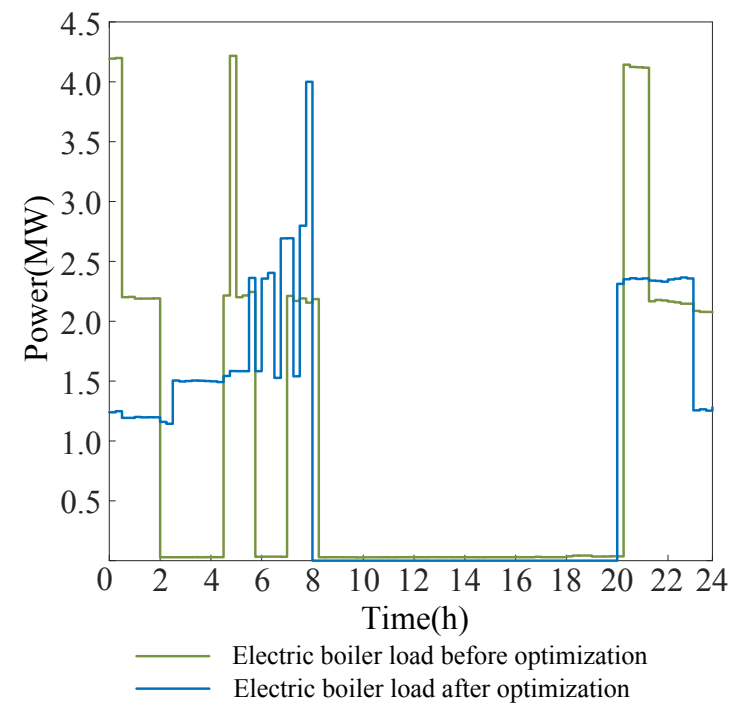

Figure 4. Operation curve of regenerative electric boiler

As can be seen from Fig. 4, when the thermal storage electric boiler is not optimized for control, the thermal storage electric boiler runs at high power at 0:00 and 20:00. The load rises sharply to the maximum, and the thermal storage electric boiler has short-term and intermittent operation, respectively at 4:00, 8:00 start and stop. The peak load appear in a very short time. However, under the optimized operation mode, the regenerative electric boiler runs at a low power at 20:00, which reduces the overlap with other non-thermal power load of the power grid during this period. In comparison, the optimized electric boiler runs continuously, reducing the number of peak load.

The optimized operating curve of the heat storage device is showed in Fig. 5. It analyzes the heat storage and release conditions of the heat storage device from the perspective of meeting the heating needs of users.

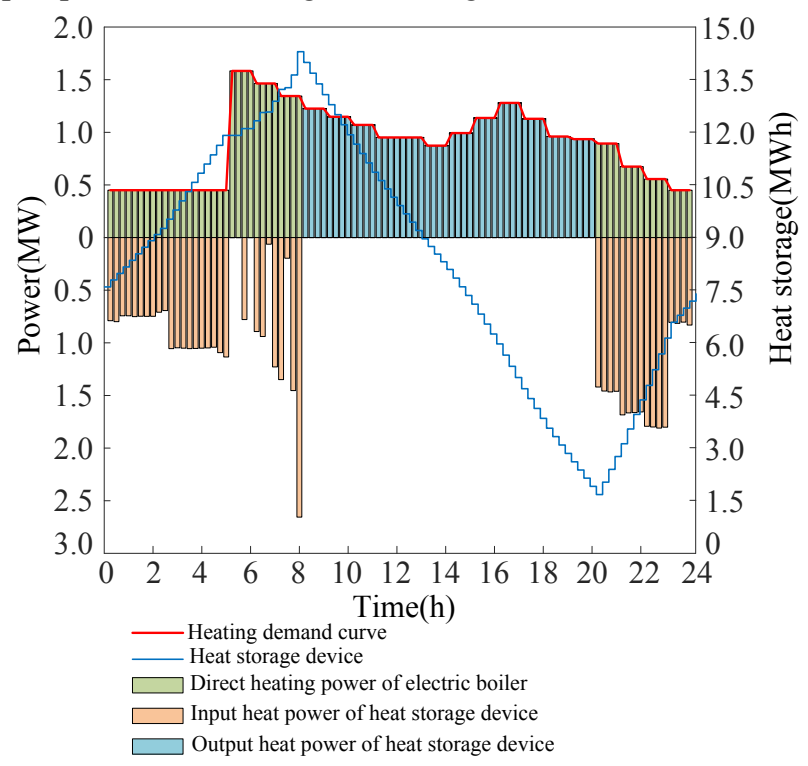

Figure 5. Heat storage and release curve of thermal storage electric heating boiler

From Fig. 5, the thermal storage electric boiler is connected to the power grid at 20:00. In addition to ensuring that the heat is directly supplied to the user during this period, the thermal storage tank stores heat at the same time, and the heat storage reaches the maximum at 8:00. After that is the peak period of electricity prices, the electric boiler stops operating, and the heat storage device starts to release heat for heating from this moment. It can be seen from the figure that the heat released by the heat storage tank can meet the heating demand of users.

\subsubsection{Electricity limiting of power grid}

Because the electricity consumption behavior of regenerative electric heating equipment is closely related to the daily life of residents, the charging of electric heating equipment connected to the grid may overlap with the peak time of daily electricity consumption. This will increase the load of distribution network in a short time, moreover, voltage drop and power line loss will increase. If the situation is serious, there may be overload operation in local distribution network area. When the above situation occurs, the power grid must be limited. At this time, the power grid should not only consider ensuring the minimum heating load demand of users, ensuring the personal safety of residents, and avoiding the freezing crack of heating network, but also supply the normal use of conventional electricity load. That is, in the case of electricity limiting of power grid, the power grid should reduce the power cut load and heat cut load. 
The operation curve of grid electric load before and after optimization under the condition of grid power restriction is showed in Fig. 6.

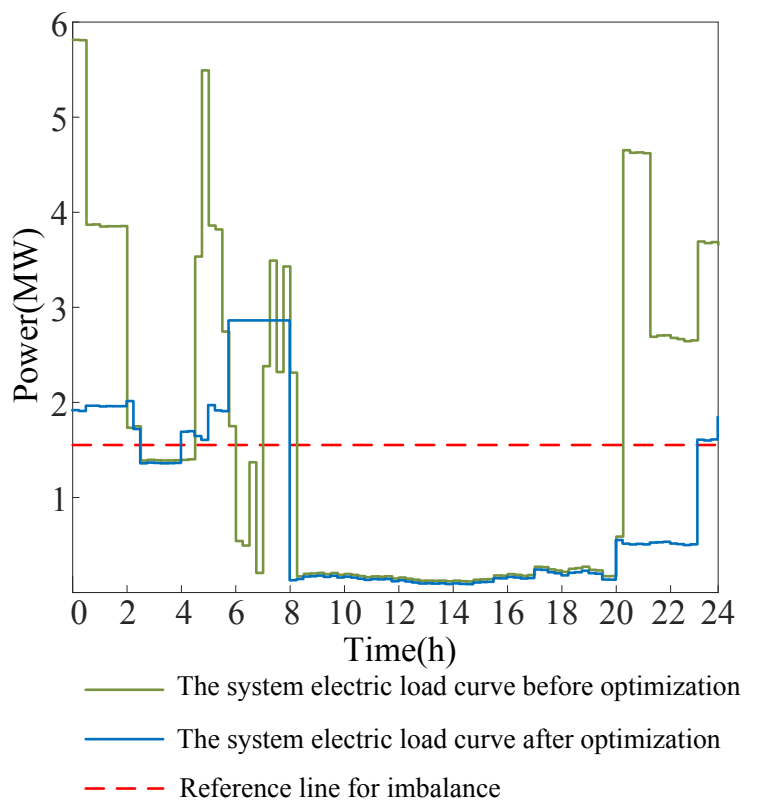

Figure 6. Grid electric load curve

From Fig.6, it can be seen that in order to meet the requirement of the electricity limiting of power grid, the electric boiler will be connected to the grid to operate after 23:00. The electric load curve has also increased significantly at the same time. $24: 00-6: 00$ is in a fluctuating state, and it remains stable from 6:00 to 8:00. Therefore, the load imbalance increase in power grid. At this time, the electricity consumption of the thermal storage electric boiler is reduced, and the heating cost of the user is also reduced accordingly. The grid load imbalance and heating costs before and after optimization are shown in Table 3.

Table 3. Load imbalance and electric heating costs before and after optimization

\begin{tabular}{|l|r|c|}
\hline \multicolumn{1}{|c|}{ Project } & $\begin{array}{c}\text { Before } \\
\text { optimization }\end{array}$ & Optimized \\
\hline Load imbalance $(\mathrm{kWh})$ & 14346.31 & 14721.53 \\
\hline Electric heating costs $(¥)$ & 5063.029 & 1371.889 \\
\hline
\end{tabular}

It can be seen from the table that the load unbalance degree of the power grid increases after optimization, and the heating cost of the users decrease. Power grid in the case of limited power, the user's electricity demand, heating demand and economy as the premise, by sacrificing the imbalance of the power grid, reduce the power load and heat load. The following figure is the operating curve of the electric boiler before and after optimization.

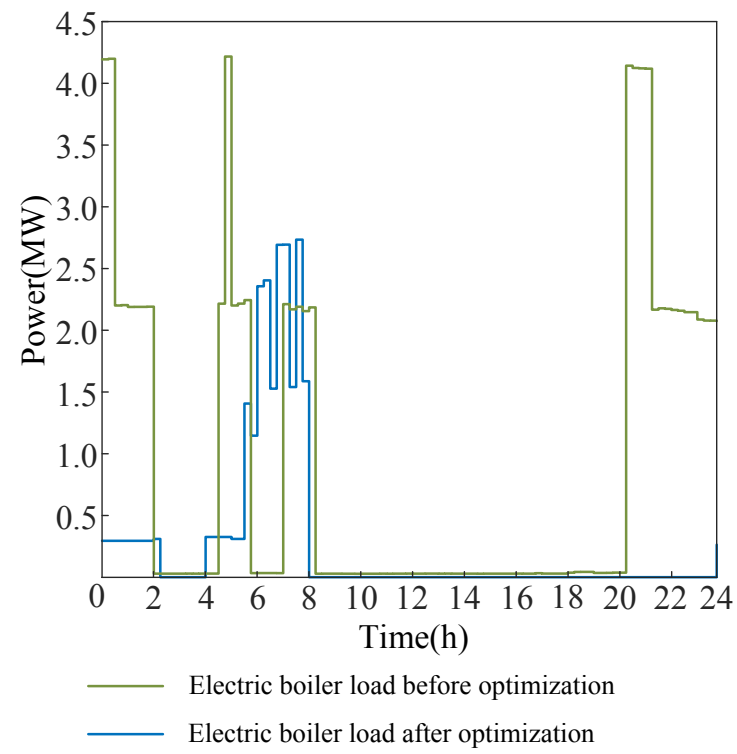

Figure 7. Operation curve of regenerative electric boiler

In the above figure, due to the emergency situation of the electricity limiting of power grid, in order to ensure the power supply of the conventional power load, the optimal scheduling of the thermal storage electric boiler is connected to the grid after 00:00, staggering the peak of daily power consumption. The electric boiler runs at a lower power between 00:00-2:00 and 4:00-6:00 in order to reduce electricity consumption, and increasing power operation from 6:00-8:00.

The heat storage and release conditions of the optimized thermal storage electric boiler is showed as figure 8 .

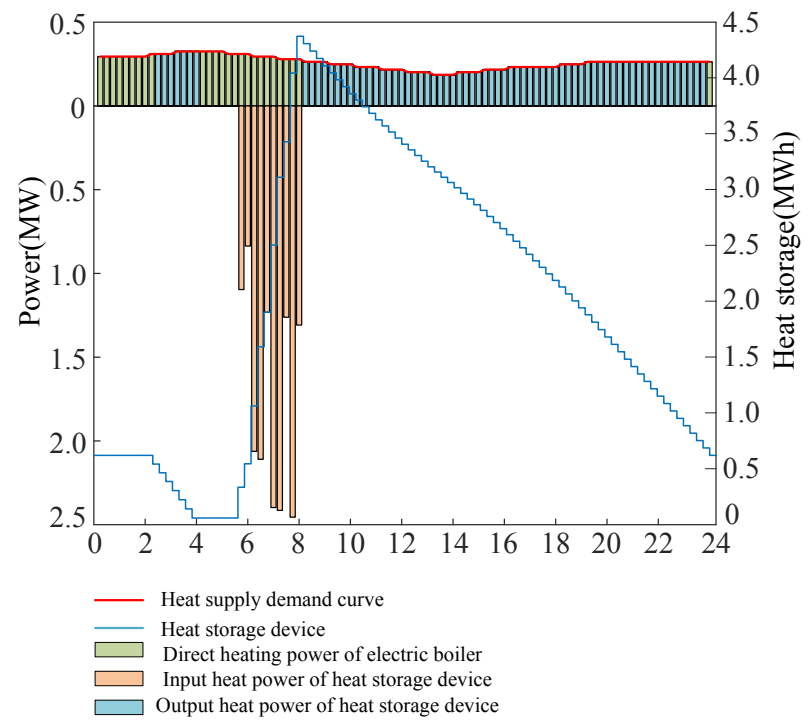

Figure 8. Heat storage and release curve of thermal storage electric heating boiler

From Fig. 8, because the electric boiler is connected to the grid at 00:00 and runs at a lower power, the heat generated by the electric boiler only supplies heat to the user without heat storage. The electric boiler stops during the period of 2:00-4:00. Then, the heat storage device uses the remaining heat storage to supply heat to the user. At 4:00, the heat storage device has released all the heat. 
At this time, the electric boiler is connected to the grid and runs at a higher power, and part of the heat generated is directly supplied to the user. Part of the heat is stored in the heat storage device. The heat storage device only stores heat at 5:00-8:00, and releases heat during other periods. Optimizing the operation of electric boiler to meet the minimum heating demand and other conventional load power supply in the case of the electricity limiting of power grid.

\section{Conclusion}

On the premise of ensuring power supply to conventional loads and heating to users, the power grid takes into account its own operating conditions. Penalty cost is used to restrict load unbalance caused by regenerative electric boiler connected to distribution network. The load adjustable ability optimizes the control of the heat storage and heat release behavior of the heat storage device, reduces the pressure on the distribution network of the electric boiler access during the winter heating period, and improves the heating economy of the system. In this paper, the optimal scheduling model proposed in this paper is analyzed from the two scenarios of normal operation and emergency power limit of power grid. And the results show that the optimized electrical boiler in the operation of the grid, the grid electricity load curve is smoother, heating costs less, verify the feasibility of the optimal scheduling strategy and effectiveness. The dispatch model in this paper can provide a certain reference for the implementation of the "coal to electricity" program and the optimal dispatch operation of combined heating of multiple electric boilers.

\section{Acknowledgments}

This work was supported by the science and technology project of State Grid Corporation of China: Key Technology and application for the optimal configuration and Market-based interaction of the regenerative electric heating (5400-201914172A-0-0-00).

\section{References}

1. National Energy Administration. Notice on Issuing the Winter Clean Heating Plan (2017-2021) in the Northern Region [EB/OL]. [2020-04-27]. http://www.gov.cn/xinwen/2017-12/20/content_5248855.html.

2. Chen Cheng, Chen Xingying, Zhang Jianzhao, etc. Stochastic operation optimization strategy of ground source heat pump system considering time-of-use electricity price $[\mathrm{J}]$. Power system protection and control, 2019, 47 (12): 57-64.

3. Fan Shuai, Jia Kunqi, Guo Bingqing, etc. Distributed electric heating load collaborative optimization operation strategy $[\mathrm{J}]$. Power system automation, 2017, 41 (19): 20-29.
4. State Grid Corporation of China. Notice on the implementation of technical measures to ensure continuous heating without power outage [EB/OL]. [2018-04-01]. http://www. chinaden. cn / news _ nr. asp ? Small_Class $=3 \&$ id $=15965$.

5. Liu Hui, Liu Qiang, Zhang Li, etc. Multi-objective planning of CCHP microgrid considering demand side collaborative response[J]. Power system protection and control, 2019, 47 (5): 43-51.

6. Chen Xinyu, Kang Chongqing, O’Malley M,et al. Increasing the flexibility of combined heat and power for wind power integration in China:Modeling and implications[J]. IEEE Transactions on Power Systems, 2015, 30 (4): 1848-1857.

7. Yuan Tian. Research on Comprehensive Benefit Evaluation and Incentive Countermeasures of 'Replacing Coal with Electricity' Heating Project[D]. North China Electric Power University, 2016.

8. Chen Xinyu, Kang Chongqing, O’MALLEY M,et al. Increasing the flexibility of combined heat and power for windpower integration in China: modeling and implications[J]. IEEE Transactions on Power Systems, 2015, 30(4): 1848-1857.

9. Chen Hongkun, Yu Yanjuan, Jiang Xin. Optimal scheduling of combined heat and power units with heat storagefor the improvement of wind power integration[C]. IEEE PESAsia-Pacific Power and Energy Engineering Conference, October 25-28, 2016, Xian, China: 1508-1512.

10. Chen Lei, Xu Fei, Wang Xiao, Min Yong, Ding Maosheng, and Huang Peng. Implementation mode and effect analysis of heat storage to improve wind power consumption capacity[J]. Journal of Electrical Engineering of China, 2015, 35 (17): 4283-4290.

11. Lv Quan, Wang Haixia, Chen Tianyou, Li Chun, Zhu Quansheng, and Li Weidong. The operation strategy of heat storage tank in thermal power plants considering wind power uncertainty $[\mathrm{J}]$. Power system automation, 2015, 39 (14): 23-29.

12. Lv Quan, Li Ling, Zhu Quansheng, Wang Haixia, Liu Enchan, Li Weidong.Comparison of coal saving effect and national economy of three kinds of abandoned wind accommodation schemes[J]. Power system automation, 2015, 39 (07): 75-83.

13. Xingtong. Value analysis and optimal scheduling model of wind power heating[D]. North China Electric Power University, 2014.

14. Lu Quan, Chen Tianyou, Wang Haixia, Li Ling, Lv Yang, Li Weidong. Electric and thermal integrated dispatching model of power system with heat storage[J]. Power automation equipment, 2014, 34 (05): 79-85.

15. Ji Wei. Modeling and simulation research on promoting wind power consumption based on electric heating[D]. Shandong University, 2014.

16. Lv Quan, Jiang Hao, Chen Tianyou, Wang Haixia, Lv Yang, Li Weidong. The scheme of wind power accommodation in thermal power plants based on 
electric boilers and its national economic evaluation[J]. Power system automation, 2014, 38 (01): 6-12.

17. Liu Hong, Wang Yes, Li Jixun, etc. Joint dispatching of rural micro-energy networks considering building thermal balance and flexible comfort[J]. Power system automation, 2019, 43 (9): 50-58.

18. Li Zhigang, Wu Wenchuan, Shahidehpour M,t al. Combined heat and power dispatch considering pipeline energy storage of district heating network[J]. IEEE Transactions on Sustainable Energy, 2016, 7 (1): $12-22$.

19. Li Zhigang, Wu Wenchuan, Wang Jianhui, et al. Transmission-constrained unit commitment considering combined electricity and district heating networks[J]. IEEE Transactions on Sustainable Energy, 2016, 7 (2): 480-492.

20. Hirth L,Ueckerdt F,Edenhofer O. Integration costs revisited-an economic framework for wind and solar variability[J]. Renewable Energy, 2015, 74: 925939.

21. CHRISTOPH J M, ALI M. Concurrent optimization ofthermal and electric storage in comme-rcial buildings to reduceoperatingcost and demand peaks under time-of-use tariffs[J]. Applied En-ergy, 2019, 254:1-12. 